\title{
Robotic gastrectomy for elderly gastric cancer patients: comparisons with robotic gastrectomy in younger patients and laparoscopic gastrectomy in the elderly
}

\author{
Naoki Okumura, ${ }^{1,4,6} \cdot$ Taeil Son $^{1,2,4} \cdot$ Yoo Min Kim ${ }^{2,3} \cdot$ Hyoung-Il Kim ${ }^{1,4} \cdot$ \\ Ji Yeong An ${ }^{1,4} \cdot$ Sung Hoon Noh ${ }^{1,4} \cdot$ Woo Jin Hyung ${ }^{1,4,5}$ (i)
}

Received: 14 January 2015/Accepted: 18 October 2015/Published online: 5 November 2015

(c) The International Gastric Cancer Association and The Japanese Gastric Cancer Association 2015

\begin{abstract}
Background Robotic surgery for gastric cancer has been adopted to overcome technical difficulties in performing laparoscopic gastrectomy. This study aimed to investigate the feasibility and safety of robotic gastrectomy in elderly gastric cancer patients.

Methods Patients who underwent laparoscopic or robotic gastrectomy from 2003 to 2010 in a single high-volume center were included in this study. We retrospectively compared preoperative characteristics, perioperative factors, and oncological parameters among an elderly ( $\geq 70$ years old) robotic gastrectomy group $(n=49)$, a younger ( $<70$ years old) robotic gastrectomy group $(n=321)$, and an elderly laparoscopic gastrectomy group $(n=132)$.

Results The elderly robotic group presented with more comorbidities than the younger robotic group. Except for
\end{abstract}

N. Okumura and T. Son contributed equally to this work.

Woo Jin Hyung

wjhyung@yuhs.ac

1 Department of Surgery, Yonsei University College of Medicine, 50 Yonsei-ro, Seodaemun-gu, Seoul 120-752, South Korea

2 Department of Surgery, Graduate School, Yonsei University College of Medicine, Seoul, South Korea

3 Department of Surgery, CHA Bundang Medical Center, CHA University School of Medicine, Seongnam, South Korea

4 Gastric Cancer Center, Yonsei Cancer Hospital, Yonsei University Health System, Seoul, South Korea

5 Robot and Minimally Invasive Surgery Center, Severance Hospital, Yonsei University Health System, Seoul, South Korea

6 Department of Surgical Oncology, Gifu University School of Medicine, Gifu, Japan number of retrieved lymph nodes (36.5 vs. 41.5; $P=0.007)$, short-term operative outcomes including complications and pathological parameters were comparable between the two robotic groups. The elderly robotic group showed comparable disease-specific survival to the younger robotic group although overall survival was worse. Compared to their laparoscopic counterparts, the elderly robotic group showed longer mean operation time (227 vs. $174 \mathrm{~min})$. Nevertheless, the incidence and severity of postoperative complications was not different between the two elderly groups. Overall and disease-specific survival were also comparable between the elderly groups. In multivariate analysis, age and surgical approach were not risk factors for overall and major complications.

Conclusions The outcomes of robotic gastrectomy in the elderly did not differ from those in younger robotic gastrectomy patients and were comparable to those in elderly patients who underwent laparoscopic gastrectomy. Thus, robotic gastrectomy could be a safe and feasible approach in elderly patients.

Keywords Gastrectomy · Robot · Laparoscopy · Elderly · Minimally invasive surgery

\section{Introduction}

Gastric cancer is the fourth leading cause of cancer mortality and is responsible for $8.8 \%$ of all cancer deaths worldwide [1]. Despite gradual decreases in its overall incidence, gastric cancer has been increasingly discovered in the elderly because of their extended life expectancy [2]. A larger number of these elderly patients are candidates for gastric resection [3]; however, a higher rate of 
comorbidities places elderly patients at greater risk of postoperative morbidity and mortality $[4,5]$.

Laparoscopic gastrectomy offers better short-term postoperative outcomes than open surgery because of its minimal invasiveness [6-10]. Laparoscopic gastrectomy is reported to be beneficial even for the elderly, showing fewer associated pulmonary and cardiac complications, compared to open surgery $[3,11]$. Nevertheless, older age and comorbidity are reported to be related to a higher incidence of systemic complications after laparoscopic gastrectomy [12].

Although laparoscopic gastrectomy has gained greater acceptance among surgeons, a limited range of movement of the laparoscopic instruments makes performing a precise lymphadenectomy difficult. As an alternative minimally invasive approach, robotic gastrectomy was introduced to overcome the limitations of laparoscopic gastrectomy, and is being increasingly performed [13-18]. However, reports on the safety and feasibility of robotic gastrectomy for elderly patients are lacking. In fact, the same concerns for potential hazards to elderly patients that were raised when laparoscopic gastrectomy was first introduced have also been raised for robotic gastrectomy, including prolonged operative time and pneumoperitoneum. To evaluate the safety and feasibility of robotic gastrectomy in elderly patients, we compared the surgical outcomes thereof with those for robotic gastrectomy in younger patients and with those for laparoscopic gastrectomy in elderly patients.

\section{Patients and methods}

\section{Patients}

From a prospective database maintained by the Department of Surgery, Yonsei University College of Medicine, we identified a total of 1465 laparoscopic $(n=1023)$ and robotic $(n=442)$ radical subtotal or total gastrectomies that were performed for patients with primary gastric adenocarcinoma between May 2003 and December 2010. Excluding patients who underwent combined operations and had a past history of gastric operations, the study included 940 patients in the laparoscopic group and 370 patients in the robotic group. Patients were then categorized according to age (elderly group, 70 years or older; younger group, younger than 70 years old). Among the patients who underwent robotic gastrectomy, 49 patients were assigned to the elderly group and 321 patients were placed in the younger robotic gastrectomy group. Of the 759 patients who underwent laparoscopic gastrectomy, 132 patients were assigned to the elderly laparoscopic gastrectomy group.
We compared preoperative patient characteristics, perioperative outcomes, and oncological parameters in the elderly robotic gastrectomy group with those in the young robotic gastrectomy group and the elderly laparoscopic gastrectomy group. Tumors were staged according to the seventh edition of the International Union Against Cancer Classification (UICC) and the American Joint Committee on Cancer (AJCC) [19]. Complications were graded according to the Clavien-Dindo classification [20].

The indications for robotic and laparoscopic gastrectomies were the same: clinically diagnosed gastric cancer without invasion to the serosal layer and without lymph node involvement in the extraperigastric area. Preoperative diagnosis was made by upper endoscopy, and clinical staging was performed with endoscopic ultrasound and abdominopelvic computed tomography. A detailed explanation of the operative systems and instruments, incision sizes, cost of surgery, and the expected postoperative course for both the robotic and laparoscopic approaches was given to each patient. Whether to undergo laparoscopic gastrectomy or robotic gastrectomy was decided by the individual patient after discussing both approaches, because the extra expenses incurred for robotic surgery are billed to the patient in Korea. All patients provided written informed consent for their operations. This retrospective study to compare surgical outcomes with other age groups and surgical techniques was approved by the Institutional Review Board (IRB) of Severance Hospital, Yonsei University College of Medicine (4-2011-0692). Because of the retrospective nature of the study, signed patient informed consent was waived per the IRB approval.

\section{Surgical technique}

The surgical techniques for the robotic and laparoscopic gastrectomies with lymph node dissection have been described in detail previously [21-24]. The da Vinci Surgical System (Intuitive Surgical, Sunnyvale, CA, USA) was used to perform all robotic gastrectomies. The extent of lymph node dissection, either D1, D1+, or D2, was determined according to the Japanese Classification of Gastric Carcinoma [25].

\section{Statistical analysis}

Data were analyzed using the Statistical Package for Social Sciences (SPSS) software, version 19.0 (IBM, Armonk, NY, USA). Factors including age, gender, body mass index (BMI), comorbidity, American Society of Anesthesiologists (ASA) score, conversion to another method, resection extent, reconstruction, lymph node dissection extent, operative time, estimated blood loss (EBL), maximum 
level of postoperative high sensitivity $\mathrm{C}$-reactive protein (hs-CRP; tested on postoperative days 0, 1, 3, and 5), postoperative complications, mortality, restoration of bowel function, and hospital stay, as well as tumor histology, size, location, margin, and TNM classification, were included for analysis. The robotic surgery in the current study was done as a clinical routine, not on an experimental basis. Thus, all parameters belong to our center's routine follow-up protocol and were derived from a prospectively designed database for the retrospective analyses. Patients were followed from the date of operation until December 31, 2012 or their death. Categorical and continuous variables were analyzed, respectively, by the chi-square test or Fisher's exact test and Student's $t$ test or Mann-Whitney $U$ test, as appropriate. Overall survival was recorded as from the time of surgery until death from any cause. Disease-specific survival was measured as the time from surgery to gastric cancer-related death. Overall and disease-specific survival curves were depicted by the Kaplan-Meier method and compared by log-rank test. Multivariate analyses were conducted to assess risk factors for complications via logistic regression analysis. All $P$ values $<0.05$ (two-sided) were considered statistically significant.

\section{Results}

\section{Clinicopathological characteristics}

Differences between the elderly robotic gastrectomy group and the two other groups are shown in Table 1. The proportion of male patients in the elderly robotic gastrectomy group $(75.5 \%)$ was higher than that in the younger robotic

Table 1 Clinicopathological characteristics

\begin{tabular}{|c|c|c|c|c|c|}
\hline Variables & $\begin{array}{l}\text { Robotic gastrectomy } \\
\text { in elderly patients }(n=49)\end{array}$ & $\begin{array}{l}\text { Robotic gastrectomy } \\
\text { in younger patients }(n=321)\end{array}$ & $P_{1}$ & $\begin{array}{l}\text { Laparoscopic gastrectomy } \\
\text { in elderly patients }(n=132)\end{array}$ & $P_{2}$ \\
\hline Age (years)* & $74.8 \pm 4.8$ & $51.1 \pm 10.2$ & $<0.001^{\mathrm{a}}$ & $73.1 \pm 3.7$ & $0.029^{\mathrm{a}}$ \\
\hline Sex & & & $0.040^{\mathrm{b}}$ & & $0.116^{\mathrm{b}}$ \\
\hline Male & $37(75.5)$ & $190(59.2)$ & & $83(62.9)$ & \\
\hline Female & $12(24.5)$ & $131(40.8)$ & & $49(37.1)$ & \\
\hline Comorbidity & & & $<0.001^{\mathrm{b}}$ & & $0.096^{\mathrm{b}}$ \\
\hline No & $9(18.4)$ & $184(57.3)$ & & $41(31.1)$ & \\
\hline Yes & 40 (81.6) & 137 (42.7) & & $91(68.9)$ & \\
\hline Hypertension & $31(63.3)$ & $61(19.0)$ & & $69(51.5)$ & \\
\hline Diabetes mellitus & $12(24.5)$ & $30(9.3)$ & & $17(12.9)$ & \\
\hline Pulmonary & $2(4.1)$ & $6(1.9)$ & & $10(7.6)$ & \\
\hline Cardiac & $7(14.3)$ & $15(4.7)$ & & $13(9.8)$ & \\
\hline Renal & $8(16.3)$ & $11(3.4)$ & & $12(9.1)$ & \\
\hline Hepatic & $3(6.1)$ & $17(5.3)$ & & $5(3.8)$ & \\
\hline CVA & $5(10.2)$ & $5(1.6)$ & & $7(5.3)$ & \\
\hline Tuberculosis & $6(12.2)$ & $21(6.5)$ & & $12(9.1)$ & \\
\hline Others & $8(16.3)$ & $36(11.2)$ & & $16(12.1)$ & \\
\hline ASA score & & & $<0.001^{\mathrm{c}}$ & & $0.572^{\mathrm{c}}$ \\
\hline 1 & $10(20.4)$ & $206(64.2)$ & & $40(30.3)$ & \\
\hline 2 & $31(63.3)$ & $96(29.9)$ & & $72(54.5)$ & \\
\hline 3 & $8(16.3)$ & $19(5.9)$ & & $19(14.4)$ & \\
\hline 4 & $0(0)$ & $0(0)$ & & $1(0.8)$ & \\
\hline BMI $\left(\mathrm{kg} / \mathrm{m}^{2}\right)^{*}$ & $24.2 \pm 3.1$ & $23.5 \pm 3.0$ & $0.118^{\mathrm{a}}$ & $24.1 \pm 3.3$ & $0.864^{\mathrm{a}}$ \\
\hline
\end{tabular}

Values in parentheses are percentages

CVA cerebrovascular accident, ASA American Society of Anesthesiologists, BMI body mass index

$P_{1}$, robotic gastrectomy in elderly patients versus robotic gastrectomy in younger patients

$P_{2}$, robotic gastrectomy in elderly patients versus laparoscopic gastrectomy in elderly patients

* Values are mean $\pm \mathrm{SD}$

a Student's $t$ test

${ }^{\mathrm{b}}$ Chi-square test

${ }^{\mathrm{c}}$ Fisher's exact test 
gastrectomy group $(59.2 \% ; P=0.04)$. As well, more elderly robotic gastrectomy patients presented with at least one comorbid condition $(81.6 \%)$ than those in the younger robotic gastrectomy group $(42.7 \% ; P<0.001)$. In regard to individual comorbid conditions, the elderly robotic gastrectomy group showed a higher prevalence of hypertension, diabetes mellitus, cardiac disease, renal disease, and cerebrovascular disease than the younger robotic gastrectomy group. Furthermore, the elderly robotic gastrectomy patients showed a higher ASA score than the younger robotic gastrectomy patients $(P<0.001)$. No significant differences in patient characteristics were noted between the elderly robotic gastrectomy and laparoscopic gastrectomy groups, except for age: the elderly robotic gastrectomy patients were older (mean, 74.8 years) than the elderly laparoscopic gastrectomy patients (mean, 73.1 years; $P=0.029$ ).

\section{Operative outcomes}

The elderly robotic gastrectomy and younger robotic gastrectomy groups exhibited no significant differences in operative outcomes (Table 2). "There was no open or laparoscopic conversion in the robotic groups, while one laparoscopic gastrectomy in an elderly patient was converted to an open gastrectomy." Mean operative time for the elderly robotic gastrectomy group (227.3 $\mathrm{min}$ ) was approximately 50 min longer than that for the elderly laparoscopic gastrectomy group (174.3 $\mathrm{min} ; P<0.001)$. However, the mean EBL of the elderly robotic gastrectomy group $(84.8 \mathrm{ml})$ was less than that of the elderly laparoscopic gastrectomy group $(156.7 \mathrm{ml})$, although the difference was not statistically significant $(P=0.056)$. As a measure of the invasiveness of the surgical procedures, maximum postoperative hs-CRP values were similar between the elderly robotic gastrectomy group (110.5 mg/l) and the elderly laparoscopic gastrectomy group $\quad(103.9 \mathrm{mg} / \mathrm{l} ; \quad P=0.543)$. Baseline hs-CRP $(P=0.277)$ and the difference between baseline and maximum postoperative hs-CRP $(P=0.502)$ were also similar between the two elderly groups.

\section{Pathological findings}

As shown in Table 3, there were no differences in tumor size and location, $\mathrm{T}$ classification, $\mathrm{N}$ classification, TNM stage, length of margin, and number of metastatic lymph nodes between the elderly and younger robotic groups. However, the proportion of patients with differentiated adenocarcinoma in the elderly robotic gastrectomy group was significantly higher than that in the younger robotic gastrectomy group $(67.3 \%$ vs. $36.1 \% ; \quad P<0.001)$. Additionally, the number of retrieved lymph nodes in the elderly robotic group ( $n=36.5$ ) was significantly smaller than that in the younger robotic group $(n=41.5$; $P=0.007)$. The number of retrieved lymph nodes in the elderly robotic group was larger compared to that of laparoscopic elderly groups, but the difference was statistically marginal $(P=0.053)$. When the number of retrieved lymph nodes was compared, based on the extent of lymph node dissection (D1+ or D2) in subtotal and total gastrectomy, no statistical differences were found between the groups, although the numbers of retrieved lymph nodes were still larger in robotic elderly groups than those in laparoscopic elderly groups, respectively. No significant differences in pathological findings, except for $\mathrm{N}$ classification $(P=0.028)$, were noted between the elderly robotic and the elderly laparoscopic groups.

\section{Short-term outcomes}

Complication rate in the elderly robotic gastrectomy group $(14.3 \%)$ did not differ from that in the younger robotic gastrectomy group $(11.8 \% ; P=0.639)$. The severity of complications in the elderly robotic group, measured according to the Clavien-Dindo classification, was also comparable to that in the younger robotic group $(P=0.633)$. Postoperative restoration of bowel function, first passage of flatus, resumption of soft diet, and hospital stay were also not significantly different between the elderly and younger robotic groups (Table 4).

As well, no statistical differences between the robotic and laparoscopic elderly groups were noted in terms of rate and severity of complications $(P=0.659, P=0.311$, respectively) or postoperative recovery. Only one instance of postoperative mortality occurred in the elderly laparoscopic group, as a consequence of intraabdominal bleeding.

\section{Multivariate analysis of risk factors for postoperative complications}

Multivariate logistic regression analysis showed male gender [hazard ratio (HR) 2.35, confidence interval (CI) 1.04-5.33) and an ASA score of 3 or 4 (HR 2.96, CI 1.15-7.63) to be significant risk factors for overall complications after robotic gastrectomy, but age was not (Table 5). Among elderly patients, male gender (HR 5.53, CI 1.64-18.65) and higher BMI (HR 1.18, CI 1.02-1.36) were risk factors for overall complications; type of approach (laparoscopic vs. robotic) was not.

With regard to major complications (grade 3 or higher according to Clavien-Dindo classification), age therefore was not shown to be a risk factor in the robotic group. As all major complications occurred in male patients, we were unable to calculate the HR and CI thereof. Among elderly patients, no variable, including type of procedure, was shown to be a risk factor for major complications. 
Table 2 Operative findings

\begin{tabular}{|c|c|c|c|c|c|}
\hline Variables & $\begin{array}{l}\text { Robotic gastrectomy } \\
\text { in elderly patients }(n=49)\end{array}$ & $\begin{array}{l}\text { Robotic gastrectomy } \\
\text { in younger patients }(n=321)\end{array}$ & $P_{1}$ & $\begin{array}{l}\text { Laparoscopic gastrectomy } \\
\text { in elderly patients }(n=132)\end{array}$ & $P_{2}$ \\
\hline Conversion & & & N/A & & $1.000^{\mathrm{a}}$ \\
\hline Yes & 0 & 0 & & $1(0.8)$ & \\
\hline No & 53 & 321 & & $131(99.2)$ & \\
\hline Resection & & & $0.389^{\mathrm{b}}$ & & $0.500^{\mathrm{b}}$ \\
\hline Distal & 39 (79.6) & $236(73.5)$ & & $112(84.8)$ & \\
\hline Total & $10(20.4)$ & $85(26.5)$ & & $20(15.2)$ & \\
\hline LN dissection & & & $1.000^{\mathrm{a}}$ & & $0.502^{\mathrm{a}}$ \\
\hline D1 & $0(0)$ & $6(1.9)$ & & $5(3.8)$ & \\
\hline D1+ & $28(57.1)$ & $179(55.8)$ & & $70(53.0)$ & \\
\hline D2 & $21(42.9)$ & $136(42.4)$ & & $57(43.2)$ & \\
\hline Operative time $(\min )^{*}$ & $227.3 \pm 47.2$ & $219.6 \pm 47.5$ & $0.290^{\mathrm{c}}$ & $174.3 \pm 55.4$ & $<0.001^{\mathrm{C}}$ \\
\hline $\mathrm{EBL}(\mathrm{ml})^{*}$ & $84.8 \pm 105.1$ & $71.4 \pm 121.0$ & $0.492^{\mathrm{c}}$ & $156.7 \pm 320.0$ & $0.056^{\mathrm{c}}$ \\
\hline \multicolumn{6}{|l|}{ hs-CRP $(\mathrm{mg} / \mathrm{l})^{\dagger}$} \\
\hline Baseline* & $1.4 \pm 1.6$ & $2.2 \pm 6.9$ & $0.521^{\mathrm{c}}$ & $2.0 \pm 3.3$ & $0.277^{\mathrm{c}}$ \\
\hline Maximum* & $110.5 \pm 49.1$ & $101.6 \pm 53.6$ & $0.361^{\mathrm{c}}$ & $103.9 \pm 52.9$ & $0.543^{\mathrm{c}}$ \\
\hline Difference $* *$ & $109.1 \pm 48.8$ & $99.4 \pm 53.6$ & $0.320^{\mathrm{c}}$ & $101.8 \pm 52.6$ & $0.502^{\mathrm{c}}$ \\
\hline
\end{tabular}

Values in parentheses are percentages

N/A not available, $L N$ lymph node, $E B L$ estimated blood loss, $h s$ - $C R P$ high-sensitivity C-reactive protein

$P_{1}$, robotic gastrectomy in elderly patients versus robotic gastrectomy in younger patients

$P_{2}$, robotic gastrectomy in elderly patients versus laparoscopic gastrectomy in elderly patients

* Values are mean $\pm \mathrm{SD}$

$\dagger$ hs-CRP was evaluated among patients without postoperative complications

* Difference between baseline and maximum postoperative hs-CRP values

a Fisher's exact test

${ }^{\mathrm{b}}$ Chi-square test

c Student's $t$ test

\section{Survival analysis}

Long-term follow up of survivors over a median of 57.8 months revealed significant differences in overall survival $(P=0.002)$ between the elderly and younger robotic gastrectomy groups, but not in disease-specific survival $(P=0.222)$ (Fig. 1$)$. Three patients in the elderly robotic gastrectomy group $(6.1 \%), 18$ patients in the younger robotic gastrectomy group (5.6\%), and 7 patients in the elderly laparoscopic gastrectomy group $(5.3 \%)$ experienced tumor recurrence during the study period. However, overall survival $(P=0.800)$ and disease-specific survival $(P=0.569)$ between the elderly robotic and laparoscopic groups were similar.

\section{Discussion}

In the present study, we found that the outcomes of robotic gastrectomy in elderly patients are comparable to those of robotic gastrectomy in younger patients, even despite the fact that a greater number of elderly patients presented with co-morbidities. Moreover, robotic gastrectomy in the elderly showed similar postoperative outcomes to laparoscopic gastrectomy in the elderly: the rate and severity of postoperative complications based on Clavien-Dindo classification were similar between the two elderly groups despite a significant difference in mean operative time. As well, overall and disease-specific survival for patients in the elderly robotic gastrectomy group were similar to those in the elderly laparoscopic gastrectomy group.

Chronological age does not seem to affect short-term outcomes, including operation time, pathological outcomes, and recovery after robotic gastrectomy. Similar to previous studies that compared laparoscopic gastrectomies between elderly and younger patients [3, 26, 27], the robotic elderly group in this study had a higher number of comorbidities than the younger robotic group; nevertheless, postoperative outcomes were similar. Previous studies also report no difference in survival between elderly and younger gastric cancer patients $[4,28]$. In this study, male 
Table 3 Pathological parameters

\begin{tabular}{|c|c|c|c|c|c|}
\hline Variables & $\begin{array}{l}\text { Robotic gastrectomy } \\
\text { in elderly patients }(n=49)\end{array}$ & $\begin{array}{l}\text { Robotic gastrectomy } \\
\text { in younger patients }(n=321)\end{array}$ & $P_{1}$ & $\begin{array}{l}\text { Laparoscopic gastrectomy } \\
\text { in elderly patients }(n=132)\end{array}$ & $P_{2}$ \\
\hline Tumor location & & & $0.456^{\mathrm{a}}$ & & $0.120^{\mathrm{a}}$ \\
\hline $\mathrm{U}$ & $9(18.4)$ & $50(15.6)$ & & $10(7.6)$ & \\
\hline M & $11(22.4)$ & $101(31.5)$ & & $32(24.2)$ & \\
\hline $\mathrm{L}$ & $29(59.2)$ & $170(53.0)$ & & $90(68.2)$ & \\
\hline Differentiation & & & $<0.001^{\mathrm{a}}$ & & $0.391^{\mathrm{a}}$ \\
\hline Differentiated & $33(67.3)$ & $116(36.1)$ & & $78(59.1)$ & \\
\hline Undifferentiated & $16(32.7)$ & $205(63.9)$ & & $54(40.9)$ & \\
\hline $\mathrm{T}$ classification & & & $0.499^{\mathrm{b}}$ & & $0.139^{\mathrm{b}}$ \\
\hline 1 & $35(71.4)$ & $250(77.9)$ & & $100(75.8)$ & \\
\hline 2 & $4(8.2)$ & $26(8.1)$ & & $20(15.2)$ & \\
\hline 3 & $7(14.3)$ & $26(8.1)$ & & $9(6.8)$ & \\
\hline $4 a$ & $3(6.1)$ & $19(5.9)$ & & $3(2.3)$ & \\
\hline $\mathrm{N}$ classification & & & $0.352^{\mathrm{b}}$ & & $0.028^{\mathrm{b}}$ \\
\hline 0 & $37(75.5)$ & $263(81.9)$ & & $109(82.6)$ & \\
\hline 1 & $8(16.3)$ & $32(10.0)$ & & $11(8.3)$ & \\
\hline 2 & $1(2.0)$ & $14(4.4)$ & & $11(8.3)$ & \\
\hline 3 & $3(6.1)$ & $12(3.7)$ & & $1(0.8)$ & \\
\hline TNM stage & & & $0.330^{\mathrm{b}}$ & & $0.166^{\mathrm{b}}$ \\
\hline Stage I & $36(73.5)$ & $263(81.9)$ & & $111(84.1)$ & \\
\hline Stage II & $8(16.3)$ & $35(10.9)$ & & $16(12.1)$ & \\
\hline Stage III & $5(10.2)$ & $23(7.2)$ & & $5(3.8)$ & \\
\hline Tumor size $(\mathrm{cm})^{*}$ & $2.7 \pm 1.4$ & $2.5 \pm 1.4$ & $0.230^{\mathrm{c}}$ & $2.7 \pm 1.5$ & $0.885^{\mathrm{c}}$ \\
\hline Proximal margin $(\mathrm{cm})^{*}$ & $4.2 \pm 2.4$ & $3.7 \pm 2.5$ & $0.271^{\mathrm{c}}$ & $4.1 \pm 2.6$ & $0.833^{\mathrm{c}}$ \\
\hline Distal margin $(\mathrm{cm})^{*}$ & $7.5 \pm 4.0$ & $7.7 \pm 4.5$ & $0.730^{\mathrm{c}}$ & $6.3 \pm 3.7$ & $0.065^{\mathrm{c}}$ \\
\hline Metastatic LN* & $0.8 \pm 2.0$ & $0.8 \pm 2.7$ & $0.959^{\mathrm{c}}$ & $0.6 \pm 1.9$ & $0.567^{\mathrm{c}}$ \\
\hline \multicolumn{6}{|l|}{ Retrieved LN* } \\
\hline All & $36.5 \pm 11.0$ & $41.5 \pm 15.7$ & $0.007^{\mathrm{c}}$ & $32.6 \pm 12.2$ & $0.053^{\mathrm{c}}$ \\
\hline STG (D1+) & $33.4 \pm 10.3$ & $37.1 \pm 14.4$ & $0.264^{\mathrm{c}}$ & $31.5 \pm 11.4$ & $0.515^{\mathrm{c}}$ \\
\hline STG (D2) & $39.4 \pm 9.9$ & $42.3 \pm 12.9$ & $0.368^{\mathrm{c}}$ & $36.4 \pm 11.8$ & $0.329^{\mathrm{c}}$ \\
\hline $\mathrm{TG}(\mathrm{D} 1+)$ & $39.0 \pm 16.0$ & $48.5 \pm 16.6$ & $0.162^{\mathrm{c}}$ & $30.0 \pm 9.3$ & $0.127^{\mathrm{c}}$ \\
\hline TG (D2) & $34.7 \pm 5.0$ & $48.5 \pm 20.3$ & $0.253^{\mathrm{c}}$ & $30.5 \pm 15.7$ & $0.676^{\mathrm{c}}$ \\
\hline Retrieved $\mathrm{LN} \geq 15$ & $48(98.0)$ & $317(98.8)$ & $0.511^{\mathrm{c}}$ & $123(93.2)$ & $0.291^{\mathrm{c}}$ \\
\hline Retrieved $\mathrm{LN}<15$ & $1(2.0)$ & $4(1.2)$ & & $9(6.8)$ & \\
\hline
\end{tabular}

Values in parentheses are percentages

$L N$ lymph node, $S T G$ subtotal gastrectomy, $T G$ total gastrectomy

$P_{1}$, robotic gastrectomy in elderly patients versus robotic gastrectomy in younger patients

$P_{2}$, robotic gastrectomy in elderly patients versus laparoscopic gastrectomy in elderly patients

* Values are mean $\pm \mathrm{SD}$

${ }^{\text {a }}$ Chi square test

b Fisher's exact test

c Student's $t$ test

gender was the only universal risk factor for postoperative complications. Male patients were older, had more comorbidity, and thus had higher ASA score than female patients in the robotic groups and underwent total gastrectomy more frequently in the elderly groups in the current study (data not shown). These findings were similar to the results of a multicenter retrospective analysis in which Korean patients underwent laparoscopic gastrectomy for gastric cancer [29]. In our study, the elderly robotic group, as well as the elderly laparoscopic group, showed significantly worse overall survival than the younger robotic group. However, disease-specific survival 
Table 4 Short-term outcomes

\begin{tabular}{|c|c|c|c|c|c|}
\hline Variables & $\begin{array}{l}\text { Robotic gastrectomy } \\
\text { in elderly patients }(n=49)\end{array}$ & $\begin{array}{l}\text { Robotic gastrectomy } \\
\text { in younger patients }(n=321)\end{array}$ & $P_{1}$ & $\begin{array}{l}\text { Laparoscopic gastrectomy } \\
\text { in elderly patients }(n=132)\end{array}$ & $P_{2}$ \\
\hline Complication & & & $0.639^{\mathrm{a}}$ & & $0.659^{\mathrm{a}}$ \\
\hline Yes & $7(14.3)$ & $38(11.8)$ & & $24(18.2)$ & \\
\hline No & $42(85.7)$ & $283(88.2)$ & & $108(81.8)$ & \\
\hline Complication grade & & & $0.633^{\mathrm{b}}$ & & $0.311^{\mathrm{b}}$ \\
\hline Grade I & $2(28.6)$ & $19(50.0)$ & & $15(62.5)$ & \\
\hline Grade II & $2(28.6)$ & $8(21.1)$ & & $4(16.7)$ & \\
\hline Grade III & $3(42.9)$ & $10(26.3)$ & & $3(12.5)$ & \\
\hline Grade IV & 0 & $1(2.6)$ & & $1(4.2)$ & \\
\hline Grade V & 0 & 0 & & $1(4.2)$ & \\
\hline Mortality & & & N/A & & $1.000^{\mathrm{b}}$ \\
\hline Yes & 0 & 0 & & $1(0.8)$ & \\
\hline No & 49 & 321 & & $131(99.2)$ & \\
\hline Gas passage $(\mathrm{POD})^{*}$ & $2[2-5]$ & $2[1-17]$ & $0.123^{\mathrm{c}}$ & $2[2-4]$ & $0.768^{\mathrm{c}}$ \\
\hline Soft diet $(\mathrm{POD})^{*}$ & $4[3-177]$ & $4[3-26]$ & $0.994^{\mathrm{c}}$ & $4[3-30]$ & $0.118^{\mathrm{c}}$ \\
\hline Hospital stay $(\mathrm{POD})^{*}$ & $5[5-203]$ & $5[5-175]$ & $0.179^{c}$ & $6[5-33]$ & $0.156^{\mathrm{c}}$ \\
\hline
\end{tabular}

Values in parentheses are percentages

N/A not available, $P O D$ postoperative day

$P_{1}$, robotic gastrectomy in elderly patients versus robotic gastrectomy in younger patients

$P 2$, robotic gastrectomy in elderly patients versus laparoscopic gastrectomy in elderly patients

* Values are median [range]

${ }^{a}$ Chi-square test

${ }^{\mathrm{b}}$ Fisher's exact test

c Mann-Whitney $U$ test

in the elderly groups, respectively, was comparable to that in the younger robotic group.

Longer operative time and prolonged exposure to pneumoperitoneum are major concerns during surgery on elderly patients, who exhibit higher rates of cardiovascular and pulmonary comorbidities that can be adversely affected by longer anesthesia and pneumoperitoneum. Nevertheless, previous studies on laparoscopic gastrectomy in elderly patients have shown that longer operative time has no harmful effect on surgical outcomes [26, 27, 30, 31]. In this study, mean operative time in the robotic elderly group was significantly longer than that in the laparoscopic elderly group, by more than $50 \mathrm{~min}$. However, as in the aforementioned studies on laparoscopic gastrectomy, the prolonged operative time and pneumoperitoneum in the elderly patients did not affect surgical outcomes (e.g., postoperative complications measured by Clavien-Dindo classification). As well, although the operative times for the robotic gastrectomies were longer than those for the laparoscopic gastrectomies, changes in serum hs-CRP levels after surgery were not statistically different between the elderly robotic gastrectomy and laparoscopic gastrectomy groups, indicating that the longer operative times of robotic surgery did not induce greater surgical stress or invasiveness in the studied patients. Therefore, although robotic gastrectomy requires a longer operative time, compared to laparoscopic gastrectomy, the lesser surgical manipulation during robotic surgery may lead to less surgical stress in the patients.

For reasons of the limitations in surgical performance, laparoscopic surgeries tend to retrieve fewer lymph nodes than open conventional surgeries [10, 32, 33]. Meanwhile, robotic surgery, which allows for more welldefined dissection under a three-dimensional surgical view, has been shown to facilitate the retrieval of a larger number of lymph nodes than laparoscopic procedures, while minimizing blood loss [34]. In the present study, the number of retrieved lymph nodes was higher and the amount of blood loss during the operation was smaller in the elderly robotic group than in the elderly laparoscopic group, although the differences were marginal. However, the higher yield of lymph nodes in the robotic elderly group compared to the laparoscopic elderly group was not shown in the subgroup analyses that were performed according to the surgical extent, probably because of the small number of cases in the subgroups. The issue should be scrutinized by prospective study with a sufficient number of patients. 
Table 5 Multivariate logistic regression analysis of risk factors for postoperative complications

\begin{tabular}{|c|c|c|c|c|c|c|c|c|}
\hline \multirow[t]{3}{*}{ Variable } & \multicolumn{4}{|c|}{ Overall complications } & \multicolumn{4}{|c|}{ Major complications } \\
\hline & \multicolumn{2}{|c|}{$\begin{array}{l}\text { Robotic gastrectomy in } \\
\text { younger and elderly } \\
\text { patients }\end{array}$} & \multicolumn{2}{|c|}{$\begin{array}{l}\text { Robotic and laparoscopic } \\
\text { gastrectomy in elderly } \\
\text { patients }\end{array}$} & \multicolumn{2}{|c|}{$\begin{array}{l}\text { Robotic gastrectomy in } \\
\text { younger and elderly } \\
\text { patients }\end{array}$} & \multicolumn{2}{|c|}{$\begin{array}{l}\text { Robotic and laparoscopic } \\
\text { gastrectomy in elderly patient }\end{array}$} \\
\hline & OR $(95 \% \mathrm{CI})$ & $P$ & OR $(95 \% \mathrm{CI})$ & $P$ & OR $(95 \% \mathrm{CI})$ & $P$ & OR $(95 \% \mathrm{CI})$ & $P$ \\
\hline \multicolumn{9}{|l|}{ Procedure } \\
\hline \multicolumn{9}{|c|}{ Laparoscopic (ref) } \\
\hline Robotic & - & - & $0.58(0.20-1.66)$ & 0.310 & - & - & $5.33(0.14-204.44)$ & 0.368 \\
\hline \multicolumn{9}{|l|}{ Age } \\
\hline Younger (ref) & & & - & - & & & - & - \\
\hline Elderly & $1.04(0.40-2.69)$ & 0.943 & & & $0.94(0.07-12.42)$ & 0.964 & & \\
\hline \multicolumn{9}{|l|}{ Sex } \\
\hline \multicolumn{9}{|l|}{ Female (ref) } \\
\hline Male & $2.35(1.04-5.33)$ & 0.040 & $5.53(1.64-18.65)$ & 0.006 & N/A & & $0.14(0.00-4.15)$ & 0.258 \\
\hline \multicolumn{9}{|l|}{ BMI } \\
\hline $\mathrm{kg} / \mathrm{m}^{2}$ & $1.10(0.98-1.24)$ & 0.104 & $1.18(1.02-1.36)$ & 0.023 & $0.92(0.66-1.27)$ & 0.598 & $0.67(0.41-1.08)$ & 0.097 \\
\hline \multicolumn{9}{|l|}{ Comorbidity } \\
\hline \multicolumn{9}{|l|}{ No (ref) } \\
\hline Yes & $0.69(0.33-1.47)$ & 0.336 & $1.17(0.41-3.37)$ & 0.766 & $0.90(0.14-5.67)$ & 0.910 & $1.71(0.09-34.13)$ & 0.726 \\
\hline \multicolumn{9}{|l|}{ ASA } \\
\hline \multicolumn{9}{|l|}{1 or 2 (ref) } \\
\hline 3 or more & $2.96(1.15-7.63)$ & 0.025 & $0.81(0.23-2.83)$ & 0.743 & $0.51(0.05-5.23)$ & 0.591 & $0.82(0.02-28.75)$ & 0.912 \\
\hline \multicolumn{9}{|l|}{ Operative time } \\
\hline Minute & $1.00(0.99-1.01)$ & 0.880 & $1.00(0.99-1.01)$ & 0.605 & $1.01(0.98-1.04)$ & 0.587 & $1.01(0.99-1.03)$ & 0.430 \\
\hline \multicolumn{9}{|l|}{ Resection } \\
\hline \multicolumn{9}{|l|}{ Subtotal (ref) } \\
\hline Total & $1.59(0.69-3.68)$ & 0.274 & $2.52(0.90-7.04)$ & 0.079 & $1.32(0.18-9.79)$ & 0.783 & $2.13(0.07-65.04)$ & 0.664 \\
\hline \multicolumn{9}{|l|}{ LN dissection } \\
\hline \multicolumn{9}{|c|}{$\mathrm{D} 1+$ or less (ref) } \\
\hline D2 & $1.57(0.78-3.17)$ & 0.206 & $1.53(0.63-3.68)$ & 0.344 & $0.38(0.05-3.13)$ & 0.371 & $10.57(0.38-293.55)$ & 0.165 \\
\hline \multicolumn{9}{|l|}{$\mathrm{T}$ classification } \\
\hline \multicolumn{9}{|l|}{ EGC (ref) } \\
\hline AGC & $1.35(0.60-3.02)$ & 0.466 & $1.33(0.47-3.76)$ & 0.586 & $5.37(0.47-60.93)$ & 0.175 & $7.82(0.35-173.05)$ & 0.193 \\
\hline \multicolumn{9}{|l|}{$\mathrm{N}$ classification } \\
\hline \multicolumn{9}{|c|}{$\mathrm{N}$ negative (ref) } \\
\hline $\mathrm{N}$ positive & $1.68(0.73-3.86)$ & 0.222 & $0.66(0.18-2.34)$ & 0.515 & $0.25(0.02-3.21)$ & 0.286 & $0.23(0.00-15.35)$ & 0.489 \\
\hline
\end{tabular}

ref reference, $B M I$ body mass index, $A S A$ American Society of Anesthesiologists, $L N$ lymph node, $E G C$ early gastric cancer, $A G C$ advanced gastric cancer, $O R$ odds ratio, $C I$ confidence interval

In general, in the present study, robotic gastrectomy in elderly gastric cancer patients was not inferior to laparoscopic gastrectomy, except for the longer operative time and higher costs. Nevertheless, in light of the results of this study, we suggest that robotic gastrectomy may hold potential benefits for elderly patients: retrieval of a larger number of lymph nodes will increase staging accuracy, and reduced intraoperative blood loss might help prevent tumor cell dissemination in the peritoneal cavity during the operation [35]. Additionally, a shorter learning curve in robotic surgery, as suggested in previous studies, could enable surgeons lacking experience with minimally invasive surgery to perform complicated procedures of this kind more readily in higher-risk patients [36-38].

As far as we know, our report is the first to evaluate robotic gastrectomy for elderly patients in a relatively large cohort, assessing long-term oncological outcomes over a sufficient follow-up period. Additionally, we compared two 
Fig. 1 Kaplan-Meier diseasespecific survival curves for the elderly robotic, younger robotic, and elderly laparoscopic gastrectomy groups (log rank; $P=0.222$, between the elderly and younger robotic groups; $P=0.569$, between the elderly robotic and laparoscopic groups)

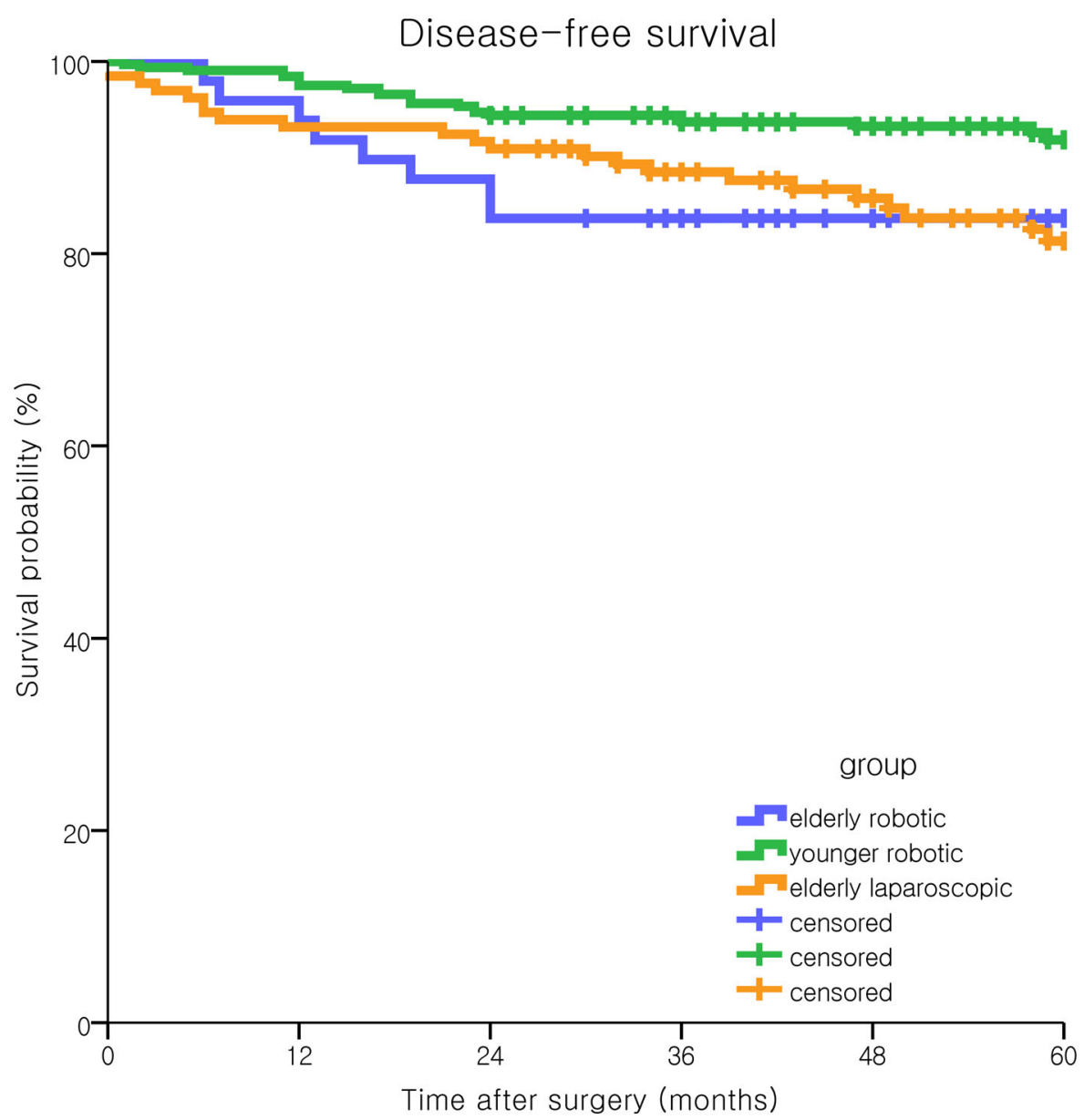

different minimally invasive techniques for treating elderly patients with gastric cancer. However, the main limitation was that our findings were derived from a single highvolume center. Data from multicenter randomized study are required to generalize the safety and efficacy of robotic gastrectomy in the elderly. Additionally, this retrospective analysis is limited by its lack of cost analyses. Results from an ongoing multicenter study (NCT01309256) will help further elucidate the role of robotic gastrectomy, in terms of cost-effectiveness, quality of life, and acute inflammatory reaction, in comparison to laparoscopic gastrectomy.

Herein, we showed that application of robotic surgery in elderly gastric patients is safe and feasible, by demonstrating that the short- and long-term outcomes thereof are comparable to those in younger robotic gastrectomy patients and elderly laparoscopic gastrectomy patients. Thus, for treating elderly patients with gastric cancer, we suggest that robotic gastrectomy is an acceptable alternative to laparoscopic gastrectomy.

Acknowledgments This study was supported by a grant from Yonsei University College of Medicine (6-2007-0097).

Conflict of interest The authors declare no conflicts of interest.

\section{References}

1. Ferlay J, Soerjomataram I, Dikshit R, Eser S, Mathers C, Rebelo $\mathrm{M}$, et al. Cancer incidence and mortality worldwide: sources, methods and major patterns in GLOBOCAN 2012. Int J Cancer. 2015;136:E359-86.

2. Saito H, Osaki T, Murakami D, Sakamoto T, Kanaji S, Tatebe S, et al. Effect of age on prognosis in patients with gastric cancer. ANZ J Surg. 2006;76:458-61.

3. Cho GS, Kim W, Kim HH, Ryu SW, Kim MC, Ryu SY. Multicentre study of the safety of laparoscopic subtotal gastrectomy for gastric cancer in the elderly. Br J Surg. 2009;96:1437-42.

4. Eguchi T, Fujii M, Takayama T. Mortality for gastric cancer in elderly patients. J Surg Oncol. 2003;84:132-6.

5. Shin HS, Oh SJ, Suh BJ. Factors related to morbidity in elderly gastric cancer patients undergoing gastrectomies. J Gastric Cancer. 2014;14:173-9.

6. Huscher CG, Mingoli A, Sgarzini G, Sansonetti A, Di Paola M, Recher A, et al. Laparoscopic versus open subtotal gastrectomy for distal gastric cancer: five-year results of a randomized prospective trial. Ann Surg. 2005;241:232-7.

7. Kim HH, Hyung WJ, Cho GS, Kim MC, Han SU, Kim W, et al. Morbidity and mortality of laparoscopic gastrectomy versus open gastrectomy for gastric cancer: an interim report-a phase III multicenter, prospective, randomized trial (KLASS trial). Ann Surg. 2010;251:417-20.

8. Kitano S, Shiraishi N, Fujii K, Yasuda K, Inomata M, Adachi Y. A randomized controlled trial comparing open vs. laparoscopy- 
assisted distal gastrectomy for the treatment of early gastric cancer: an interim report. Surgery (St. Louis). 2002;131(1 suppl):S306-11.

9. Kodera Y, Fujiwara M, Ohashi N, Nakayama G, Koike M, Morita $\mathrm{S}$, et al. Laparoscopic surgery for gastric cancer: a collective review with meta-analysis of randomized trials. J Am Coll Surg. 2010;211:677-86.

10. Memon MA, Khan S, Yunus RM, Barr R, Memon B. Metaanalysis of laparoscopic and open distal gastrectomy for gastric carcinoma. Surg Endosc. 2008;22:1781-9.

11. Yamada H, Kojima K, Inokuchi M, Kawano T, Sugihara K. Laparoscopy-assisted gastrectomy in patients older than 80 . J Surg Res. 2010;161:259-63.

12. Kim W, Song KY, Lee HJ, Han SU, Hyung WJ, Cho GS. The impact of comorbidity on surgical outcomes in laparoscopy-assisted distal gastrectomy: a retrospective analysis of multicenter results. Ann Surg. 2008;248:793-9.

13. Hashizume M, Shimada M, Tomikawa M, Ikeda Y, Takahashi I, Abe R, et al. Early experiences of endoscopic procedures in general surgery assisted by a computer-enhanced surgical system. Surg Endosc. 2002;16:1187-91.

14. Giulianotti PC, Coratti A, Angelini M, Sbrana F, Cecconi S, Balestracci $\mathrm{T}$, et al. Robotics in general surgery: personal experience in a large community hospital. Arch Surg. 2003;138:777-84.

15. Hashizume M, Sugimachi K. Robot-assisted gastric surgery. Surg Clin N Am. 2003;83:1429-44.

16. Kim MC, Heo GU, Jung GJ. Robotic gastrectomy for gastric cancer: surgical techniques and clinical merits. Surg Endosc. 2010;24:610-5.

17. Buchs NC, Bucher P, Pugin F, Morel P. Robot-assisted gastrectomy for cancer. Minerva Gastroenterol Dietol. 2011;57:33-42.

18. Park JY, Kim YW, Ryu KW, Eom BW, Yoon HM, Reim D. Emerging role of robot-assisted gastrectomy: analysis of consecutive 200 cases. J Gastric Cancer. 2013;13:255-62.

19. Edge SB, Byrd DR, Compton CC, Fritz AG, Greene FL, Trotti A, et al., American Joint Committee on Cancer (AJCC). AJCC cancer staging manual. 7th ed. New York: Springer; 2010.

20. Dindo D, Demartines N, Clavien PA. Classification of surgical complications: a new proposal with evaluation in a cohort of 6336 patients and results of a survey. Ann Surg. 2004;240:205-13.

21. Song J, Kang WH, Oh SJ, Hyung WJ, Choi SH, Noh SH. Role of robotic gastrectomy using da Vinci system compared with laparoscopic gastrectomy: initial experience of 20 consecutive cases. Surg Endosc. 2009;23:1204-11.

22. Woo Y, Hyung WJ, Pak KH, Inaba K, Obama K, Choi SH, et al. Robotic gastrectomy as an oncologically sound alternative to laparoscopic resections for the treatment of early-stage gastric cancers. Arch Surg. 2011;146:1086-92.

23. Hyung WJ, Lim JS, Song J, Choi SH, Noh SH. Laparoscopic spleen-preserving splenic hilar lymph node dissection during total gastrectomy for gastric cancer. J Am Coll Surg. 2008;207:e6-11.

24. Hyung WJ, Song C, Cheong JH, Choi SH, Noh SH. Factors influencing operation time of laparoscopy-assisted distal subtotal gastrectomy: analysis of consecutive 100 initial cases. Eur J Surg Oncol. 2007;33:314-9.

25. Japanese Gastric Cancer Association. Japanese gastric cancer treatment guidelines (ver. 3). Gastric Cancer. 2010;2011(14):113-23.

26. Hwang SH, Park do J, Jee YS, Kim HH, Lee HJ, Yang HK, et al. Risk factors for operative complications in elderly patients during laparoscopy-assisted gastrectomy. J Am Coll Surg. 2009;208:186-92.

27. Tokunaga M, Hiki N, Fukunaga T, Miki A, Ohyama S, Seto Y, et al. Does age matter in the indication for laparoscopy-assisted gastrectomy? J Gastrointest Surg. 2008;12:1502-7.

28. Kwon IG, Cho I, Guner A, Kim HI, Noh SH, Hyung WJ. Minimally invasive surgery as a treatment option for gastric cancer in the elderly: comparison with open surgery for patients 80 years and older. Surg Endosc. 2015;29:2321-30.

29. Kim MC, Kim W, Kim HH, Ryu SW, Ryu SY, Song KY, Korean Laparoscopic Gastrointestinal Surgery Study (KLASS) Group, et al. Risk factors associated with complication following laparoscopy-assisted gastrectomy for gastric cancer: a large-scale Korean multicenter study. Ann Surg Oncol. 2008;15:2692-700.

30. Mochiki E, Ohno T, Kamiyama Y, Aihara R, Nakabayashi T, Asao $\mathrm{T}$, et al. Laparoscopy-assisted gastrectomy for early gastric cancer in young and elderly patients. World J Surg. 2005;29:1585-91.

31. Yasuda K, Sonoda K, Shiroshita H, Inomata M, Shiraishi N, Kitano S. Laparoscopically assisted distal gastrectomy for early gastric cancer in the elderly. Br J Surg. 2004;91:1061-5.

32. Ohtani H, Tamamori Y, Noguchi K, Azuma T, Fujimoto S, Oba $\mathrm{H}$, et al. Meta-analysis of laparoscopy-assisted and open distal gastrectomy for gastric cancer. J Surg Res. 2011;171:479-85.

33. Vinuela EF, Gonen M, Brennan MF, Coit DG, Strong VE. Laparoscopic versus open distal gastrectomy for gastric cancer: a meta-analysis of randomized controlled trials and high-quality nonrandomized studies. Ann Surg. 2012;255:446-56.

34. Son T, Lee JH, Kim YM, Kim HI, Noh SH, Hyung WJ. Robotic spleen-preserving total gastrectomy for gastric cancer: comparison with conventional laparoscopic procedure. Surg Endosc. 2014;28:2606-15.

35. Han TS, Kong SH, Lee HJ, Ahn HS, Hur K, Yu J, et al. Dissemination of free cancer cells from the gastric lumen and from perigastric lymphovascular pedicles during radical gastric cancer surgery. Ann Surg Oncol. 2011;18:2818-25.

36. Kim HI, Park MS, Song KJ, Woo Y, Hyung WJ. Rapid and safe learning of robotic gastrectomy for gastric cancer: multidimensional analysis in a comparison with laparoscopic gastrectomy. Eur J Surg Oncol. 2014;40:1346-54.

37. Park SS, Kim MC, Park MS, Hyung WJ. Rapid adaptation of robotic gastrectomy for gastric cancer by experienced laparoscopic surgeons. Surg Endosc. 2012;26:60-7.

38. Kang BH, Xuan Y, Hur H, Ahn CW, Cho YK, Han SU. Comparison of surgical outcomes between robotic and laparoscopic gastrectomy for gastric cancer: the learning curve of robotic surgery. J Gastric Cancer. 2012;12:156-63. 